\title{
EFEITO DA PELETIZAÇÃO EM DIETAS CONTENDO COMPLEXO ENZIMÁTICO PARA FRANGOS DE CORTE
}

\author{
Marta Helena Dias da Silveira, ${ }^{1}$ Jerri Teixeira Zan usso, ${ }^{2}$ Patrícia Rossi, ${ }^{3}$ Fernando Rutz, ${ }^{2}$ \\ Marco Antonio Anciuti,4 Niedi Franz Zauk, ${ }^{5}$ Carmen Lucia Garcez Ribeiro, ${ }^{5}$ \\ Paulo Antonio Rabenschlag Brum ${ }^{6}$ e Juliana Klug Nunes ${ }^{5}$
}

1. Professora, Universidade Tecnológica Federal do Paraná, Pato Branco, PR. E-mail: martasilveira@utfpr.edu.br

2. Professores do Departamento de Zootecnia da Universidade Federal de Pelotas, Pelotas, RS

3. University of Kentucky, Department Animal and Food Sciences, Lexington, KY, USA

4. Professor do Conjunto Agrotécnico Visconde da Graça - Pelotas, RS

5. Aluna do Programa de Pós-Graduação em Zootecnia, UFPEL, Pelotas, RS

6. Embrapa Suinos e Aves, Concordia, SC.

\section{RESUMO}

O trabalho teve como objetivo avaliar se a peletização interfere na atividade enzimática de dietas com um complexo enzimático (CE) produzido utilizando a tecnologia de fermentação no estado sólido. Alojaram-se 216 frangos de corte machos Cobb (1 a 21 dias de idade) em baterias, num total de seis repetições por tratamento e seis aves por tratamento. Os tratamentos consistiram em T1: dieta-controle farelada; T2: dieta-controle peletizada; T3: dieta superestimada com CE farelada; T4: dieta superestimada sem CE farelada; T5: dieta superestimada com CE peletizada; T6: dieta superestimada sem CE peletizada. Reformularam-se dietas com superestimação de $75 \mathrm{kcal} \mathrm{EM} / \mathrm{kg}, 0.1 \%$ Ca e P. Observou-se que houve um aumento no ganho de peso, coxa e sobrecoxa com o uso de dieta peletizada. A coloração da carne não foi influenciada pelos tratamentos. Resultados indicaram que dietas com o complexo enzimático não foram afetadas pela peletização $\left(75^{\circ} \mathrm{C}\right)$.

PALAVRAS-CHAVES: Cor da carne, desempenho, frango de corte, pellets, resistência óssea.

\section{ABSTRACT}

\section{EFFECT OF PELLETIZATION ON DIETS CONTAINING AN ENZYMATIC COMPLEX TO BROILER CHICKENS}

This study aimed to examine if pelletization interferes in the dietary enzymatic activity, in which an enzymatic complex (EC) produced by solid state fermentation technology was used. A total of 216 Cobb male broilers ( 1 to 21 days of age) were allocated in batteries. A total of 6 replicates per treatment, and 6 broilers per treatment were used. Treatments consisted of T1- Control mash diet, T2-Control pellet diet, T3- Overestimated mash diet + EC, T4- overestimated mash diet without addition of EC, T5- Overestimated pellet diet + EC, and T6- overestimated pellet diet without addition of EC. All overestimated diets were reformulated to $75 \mathrm{kcal} \mathrm{ME} /$ $\mathrm{kg}, 0.1 \% \mathrm{Ca}$ and $\mathrm{P}$. Growth performance, drumstick and thigh were increased with the use of pellet diet. Meat color was not influenced by dietary treatments. Results indicated that the enzymatic complex was not affected by pelleting $\left(75^{\circ} \mathrm{C}\right)$ the diets.

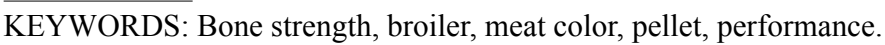




\section{INTRODUÇÃO}

Têm ocorrido grandes avanços na avicultura e, diante disso, os nutricionistas buscam alternativas que tornem a ração mais eficiente e econômica, por ser o item de maior custo na produção dos frangos de corte. Atualmente, para a exportação de frangos de corte, não se pode utilizar produtos de origem animal na ração e, além disso, o preço do milho e soja vem aumentando em função do etanol e do biodiesel. De acordo com WYATT \& BEDFORD (1998), é possível reformular dietas para reduzir custos sem prejudicar o desempenho produtivo dos animais. As enzimas exercem um efeito considerável na redução da poluição ambiental. Além disso, seu efeito redutor de custo de formulação e o efeito antinutricional de alguns ingredientes têm tornado seu uso mais efetivo pelas empresas (LECZNIESKI, 2006).

O uso de enzimas na formulação de dietas comerciais para frangos de corte tem sido uma opção viável para os produtores, dadas as respostas positivas na digestibilidade dos alimentos e no desempenho das aves, afetando diretamente a eficiência produtiva (ALBINO et al., 2007).

ZANELLA et al. (1999) demonstraram que a adição de um complexo multienzimático em dietas de frangos de corte, formuladas à base de milho e soja integral tostada e extrusada, melhorou a digestibilidade da proteína e do amido das dietas. TORRES et al. (2003) e COSTA et al. (2004) verificaram que aves alimentadas com dietas à base de milho e farelo de soja, suplementadas com complexo enzimático, tiveram melhor digestibilidade de nutrientes e melhor desempenho produtivo.

A maioria das especificações dos nutrientes é estabelecida com o alimento farelado, e elas podem não ser as mesmas para o alimento peletizado. Além disso, torna-se fundamental fazer um controle criterioso do que está acontecendo com a enzima adicionada à ração. Deve-se fazer um monitoramento contínuo não somente por fábrica, mas também por linha de produção, uma vez que as fábricas de ração não são iguais umas às outras e ainda, numa mesma fábrica, pode haver linhas de produção com condições diferentes entre si (temperatura de processamento, pressão de vapor, tempo de condicionamento, tipos de equipamentos, capacidade de produção etc.). A composição dos ingredientes na dieta pode ter um impacto importante sobre a qualidade dos peletes, já que diferentes ingredientes relacionam-se de forma diferente com o vapor, a pressão e a temperatura do processo de peletização (KLEIN et al., 1996).

Para uma boa utilização de enzimas, sua atividade biológica deve sobreviver aos rigores da fabricação e armazenagem da ração, resistir ao baixo $\mathrm{pH}$ e às enzimas proteolíticas do trato digestório. Quando o alimento é submetido a temperaturas elevadas, como nos processos de peletização e extrusão, pode ocorrer desnaturação das enzimas, eliminando o benefício de sua inclusão na dieta dos animais (SARTORI, 1999).

ROSE \& ARSCOTT (1960) concluíram que, durante o processo de peletização, ocorrem sensíveis alterações na estrutura do amido dos cereais, tornando-o mais sensível ao ataque das enzimas responsáveis pela digestão, o que justifica, em grande parte, a melhora de resultados conseguidos com as rações peletizadas. $\mathrm{O}$ processo de peletização de uma ração aumenta o seu teor de energia produtiva, pela redução do tempo de ingestão e pela redução da energia gasta na preensão do alimento (REDDY et al., 1961). De acordo com FLEMMING (2002), aves que receberam ração peletizada gastaram $4 \%$ do tempo na ingestão de alimentos e aquelas que receberam ração farelada gastaram $15 \%$.

As enzimas utilizadas na alimentação de não ruminantes devem resistir e conservar atividade considerável depois dos processos de fabricação, já que as dietas peletizadas são submetidas a condições adversas de temperatura, umidade e pressão. Fatores como tempo de condicionamento, temperatura e pressão de vapor são críticos para estabilidade da enzima na ração (FRANCESCH, 1996; LECZNIESKI, 2006).

Segundo GRAHAM \& INBORR (1991), citados por BORGES (1997), a estrutura molecular das enzimas é bastante frágil e, consequentemente, pode ser desnaturada por calor, álcalis, metais pesados e outros agentes oxidantes. O calor do processo de peletização pode inativar permanentemente as enzimas, e a enzima ideal deve ser capaz de suportar temperaturas entre $70^{\circ}$ e $90^{\circ} \mathrm{C}$, normalmente alcançadas durante o processo de peletização.

Assim, objetivou-se avaliar se o processo de peletização interfere na eficiência das enzimas adicionadas à dieta, influenciando o desempenho produtivo, 
o rendimento de cortes, a cor do músculo peitoral e a resistência óssea de frangos de corte no período de 1 a 21 dias de idade.

\section{MATERIAL E MÉTODOS}

O complexo enzimático (CE) ${ }^{1}$ utilizado neste trabalho era composto pelas enzimas fitase, protease, xilanase, $\beta$-glucanase, celulase, amilase e pectinase. Foi produzido por ação fúngica utilizando tecnologia em fermentação em estado sólido, que permite obter uma maior digestibilidade dos ingredientes vegetais que compõem a dieta.

O experimento foi desenvolvido no aviário experimental do Departamento de Zootecnia da Universidade Federal de Pelotas (DZ/UFPEL), num período de 21 dias, durante o período de 20 de dezembro de 2005 a 10 de janeiro 2006. Alojaram-se 216 pintos de corte, machos, da linhagem Ross com um dia de idade, em dois conjuntos de baterias de cinco andares, divididos em quatro repartições de $90 \mathrm{~cm}$ de comprimento $\mathrm{x} 40$ $\mathrm{cm}$ de largura x $30 \mathrm{~cm}$ de altura cada. $\mathrm{O}$ sistema de aquecimento utilizado foi através de resistência, sendo as ligações feitas doze horas antes do alojamento e mantidas nos primeiros dias por 24 horas. Depois foram manejadas conforme a temperatura ambiente interna no aviário, seguindo as recomendações do manual da linhagem Ross. Diariamente, era realizado o monitoramento das temperaturas máxima e mínima e da taxa de umidade relativa do ar interna do galpão experimental. No piso de tela metálica, colocaram-se papel e bandejas com ração inicial, sendo retirados ao final de três dias. $\mathrm{O}$ fornecimento de água e ração foi realizado por bebedouro e comedouro do tipo calha acoplado nas baterias.

Ao chegarem, os pintos foram pesados individualmente e distribuídos nos boxes com um peso corporal médio de $\pm 46 \mathrm{~g}$. Os tratamentos consistiram de $\mathrm{T} 1$ - dieta controle farelada; T2 - dieta controle peletizada; T3 dieta superestimada ( $75 \mathrm{kcal} \mathrm{ME} / \mathrm{kg}, 0.1 \% \mathrm{Ca}, 0.1 \% \mathrm{Pi}$ ) com SSF farelada; T4 - dieta superestimada (75 kcal $\mathrm{ME} / \mathrm{kg}, 0.1 \% \mathrm{Ca}, 0.1 \% \mathrm{Pi}$ ) sem SSF farelada; T5 - dieta superestimada (75 kcal ME/kg, 0.1\% Ca, 0.1\%Pi) com SSF peletizada; T6 - dieta superestimada ( $75 \mathrm{kcal} \mathrm{ME/}$ $\mathrm{kg}, 0.1 \% \mathrm{Ca}, 0.1 \% \mathrm{Pi}$ ) sem SSF peletizada.

1. Allzyme SSF, Altech Inc. produzido pela Alltech do Brasil Agroindustrial Ltda.
O programa de alimentação foi realizado para produção de aves de 1 a 21 dias (Tabela 1), à base de milho e farelo de soja, reformulado de forma a superestimar a energia metabolizável em $75 \mathrm{kcal} \mathrm{EM} / \mathrm{kg}$, o fósforo inorgânico em $0,1 \%$ e o cálcio em $0,1 \%$. Incluiu-se o CE nas dietas na quantidade de $200 \mathrm{~g}$ para cada $1.000 \mathrm{~kg}$, segundo recomendações do fabricante. As dietas experimentais foram preparadas pelo processo de mistura convencional na fábrica de ração da EMBRAPA-CNPSA (Concórdia - SC). Ensacou-se a parte que seria fornecida como farelada, peletizandose a outra parte com peneira de 4,0 mm (3/32), e com temperatura interna $75^{\circ} \mathrm{C}$.

Analisaram-se as seguintes variáveis: consumo de ração (CR), ganho de peso (GP), conversão alimentar (CA), taxa de mortalidade (TM) e índice de eficiência produtiva ((viabilidade $\mathrm{x}$ ganho de peso (kg) /consumo x CA) x 100). Ao final de 21 dias, pesaram-se todas as aves, sendo retirada uma ave por unidade experimental com peso corporal de $\pm 10 \%$ da média da repetição. Realizou-se o abate no Abatedouro Experimental do Conjunto Agrotécnico Visconde da Graça da Universidade Federal de Pelotas (CAVG/ UFPEL), sendo separados, para determinação do rendimento, o peito, as coxas e as sobrecoxas, os quais foram utilizados para determinação do percentual de cinzas e resistência óssea.

Das coxas e sobrecoxas direitas, extraíram-se os ossos tíbia e fêmur, sendo pesados e desengorduras para o cálculo do percentual de cinzas. Para a retirada de gordura, mantiveram-se os ossos imersos em éter por doze horas. Após, foram expostos ao meio ambiente, para volatilização, e colocados em estufa à temperatura de $105^{\circ} \mathrm{C}$ durante 24 horas, para determinação da matéria seca. Posteriormente, foram colocados na mufla a $600^{\circ} \mathrm{C}$ por doze horas, para determinação das cinzas. Destinaram-se os ossos do fêmur e a tíbia esquerda, in natura, para análises de resistência óssea, em prensa computadorizada (Instron Universal Testing Machine - modelo 1130). Os ossos foram colocados na posição horizontal sobre dois suportes, sendo a pressão aplicada no centro deles. A quantidade máxima de força aplicada ao osso antes de sua ruptura é considerada como resistência à quebra dos ossos.

Para determinação da cor, o músculo peitoral maior (Pectoralis major) de cada ave foi identificado, embalado em filme plástico e congelado a $-18^{\circ} \mathrm{C}$. Para 
análise, descongelaram-se as amostras a $4^{\circ} \mathrm{C}$ durante 24 horas. Após esse período, procedeu-se às leituras com um colorímetro Minolta ${ }^{\circledR}$ (modelo CR-300), sobre placa plástica branca, e à calibração, em ladrilho cerâmico branco. O sistema utilizado foi o L*a*b*, (McLAREN, 1976), em que o $L$ corresponde à luminosidade, $a$ ao índice de vermelho (variando de verde a vermelho), e $b$ ao índice de amarelo (variando de amarelo a azul). Em cada peitoral, efetuaram-se três leituras em pontos diferentes (porção cranial, mediana e caudal), sendo o resultado expresso como a média dessas leituras.

O delineamento experimental utilizado foi em blocos ao acaso, com seis tratamentos de seis repetições e com seis aves por unidade experimental. Os dados foram submetidos à analise de variância e as médias comparadas por meio de contrastes ao nível de $5 \%$ de probabilidade, utilizando-se o programa estatístico SAS.

TABELA 1. Composição das dietas experimentais consumidas por frangos de 1 a 21 dias de idade

\begin{tabular}{|c|c|c|c|c|c|c|}
\hline Ingredientes (\%) & $\mathrm{T} 1$ & $\mathrm{~T} 2$ & $\mathrm{~T} 3$ & $\mathrm{~T} 4$ & T5 & T6 \\
\hline Milho & 59,07 & 59,07 & 62,47 & 62,47 & 62,47 & 62,47 \\
\hline Farelo de soja & 34,70 & 34,70 & 33,70 & 33,70 & 33,70 & 33,70 \\
\hline Calcário calcítico & 1,20 & 1,20 & 1,20 & 1,20 & 1,20 & 1,20 \\
\hline Sal comum & 0,43 & 0,43 & 0,43 & 0,43 & 0,43 & 0,43 \\
\hline Fosfato bicálcico & 1,82 & 1,82 & 1,26 & 1,26 & 1,26 & 1,20 \\
\hline Óleo de soja & 2,28 & 2,28 & 0,42 & 0,42 & 0,42 & 0,42 \\
\hline Suplemento vitamínico e mineral ${ }^{1}$ & 0,50 & 0,50 & 0,50 & 0,50 & 0,50 & 0,50 \\
\hline Caulim & 0,00 & 0,00 & 0,00 & 0,02 & 0,00 & 0,02 \\
\hline $\mathrm{CE}^{2}$ & 0,00 & 0,00 & 0,02 & 0,00 & 0,02 & 0,00 \\
\hline Total (kg) & 100 & 100 & 100 & 100 & 100 & 100 \\
\hline Custo (kg) & 0,67 & 0,67 & 0,64 & 0,64 & 0,64 & 0,63 \\
\hline \multicolumn{7}{|l|}{ Níveis nutricionais calculados } \\
\hline EM (kcal/kg) & 2950 & 2950 & 2950 & 2950 & 2950 & 2950 \\
\hline Proteína bruta (\%) & 21,88 & 21,88 & 21,88 & 21,88 & 21,88 & 21,88 \\
\hline Cálcio (\%) & 0,9 & 0,9 & 0,9 & 0,9 & 0,9 & 0,9 \\
\hline Fósforo disponível (\%) & 0,45 & 0,45 & 0,45 & 0,45 & 0,45 & 0,45 \\
\hline Metionina digestível (\%) & 0,53 & 0,53 & 0,53 & 0,53 & 0,53 & 0,53 \\
\hline Lisina total (mg/kg) & 1,15 & 1,15 & 1,15 & 1,15 & 1,15 & 1,15 \\
\hline Colina sintética $(\mathrm{mg} / \mathrm{kg})$ & 1280 & 1280 & 1280 & 1280 & 1280 & 1280 \\
\hline Ácido linoleico (\%) & 3,31 & 3,31 & 3,31 & 3,31 & 3,31 & 3,31 \\
\hline
\end{tabular}

${ }^{1}$ Níveis de garantia/kg do produto: vit A, 2.000.000 UI; vit B12, 2.400 mcg; manganês, 20.000 mg;vit D, $400.000 U I ;$ niacina, 8.000 mg; zinco, $12.000 \mathrm{mg}$; vit E, $3.000 \mathrm{mg}$; ácido fólico, $215 \mathrm{mg}$; ferro, $10.000 \mathrm{mg}$; vit K, $340 \mathrm{mg}$; ácido pantotênico, $3.200 \mathrm{mg}$; cobre, 1.995 mg; vit B1, $360 \mathrm{mg}$; biotina, $16 \mathrm{mg}$; iodo, $120 \mathrm{mg}$; vit B2, $1.200 \mathrm{mg}$; metionina, $360 \mathrm{~g}$; selênio, $65 \mathrm{mg}$; vit B6, $500 \mathrm{mg}$; colina, $100 \mathrm{~g}$. ${ }^{2}$ Allzyme SSF $=\mathrm{CE}=200 \mathrm{~g} / 1000 \mathrm{~kg}=20 \mathrm{~g} / 100 \mathrm{~kg}=0,2$.

\section{RESULTADOS E DISCUSSÃO}

Os dados de desempenho produtivo dos frangos de corte alimentados com dietas fareladas ou peletizadas, com ou sem enzimas, no período de 21 dias, são apresentados na Tabela 2.
Não houve efeito significativo dos tratamentos sobre o CR, TM e IEP. Entretanto, observou-se efeito $(\mathrm{P}<0,01)$ dos tratamentos sobre o GP e CA. Esses resultados discordam dos apresentados por GARCIA (2003), que verificou CR em frangos de corte, quando dietas fareladas e peletizadas à base de milho e soja 
foram suplementadas com as enzimas amilase, xilanase e protease.

As aves que receberam ração peletizada tiveram maiores GP e melhor CA, quando comparadas com as que receberam ração farelada, independente da presença do CE. Isso se deve, provavelmente, ao menor desperdício de ração e à maior concentração de nutrientes resultantes da peletização, ao passo que, com o uso de ração farelada, dependendo da sua granulometria, a ave seleciona as partículas maiores, o que causa um desequilíbrio nutricional e, consequentemente, piora no desempenho. No entanto, HAMILTON \& PROUDFOOT (1995), comparando diferentes granulometrias em dietas fareladas, observaram que o peso corporal aumentou quando a granulometria das dietas foi aumentada. BUSTANY (1996), ao alimentar pintainhos com dieta peletizada, verificou um GP de $7,8 \%$ sobre as aves alimentadas com ração farelada, concluindo que pintainhos alimentados com dietas fareladas eram incapazes de ajustar o consumo, dada a baixa concentração de nutrientes nas partículas dos ingredientes.

LEITE (2006) comparou dieta farelada com duas dietas peletizadas. As dietas foram formuladas contendo ou não CE (Allzyme ${ }^{\circledR}$ Vegpro), sendo as peletizadas adicionadas de minerais e vitaminas antes e após a peletização. O autor observou que o GP melhorou em 3,31\% quando se utilizou a ração farelada com enzimas. E no caso das rações peletizadas com enzimas e com adição de vitaminas e minerais antes da peletização, observaram-se melhorias no GP de 1,78\% em relação às dietas não suplementadas.

Independente da adição de $\mathrm{CE}$, as dietas peletizadas (dieta-controle peletizada, dieta superestimada com CE peletizada; dieta superestimada sem CE peletizada) apresentaram melhor $\mathrm{CA}(\mathrm{P}<0,05)$, em comparação com os valores obtidos com a ração farelada, indicando que a peletização melhorou a digestibilidade e absorção dos nutrientes.

TABELA 2. Médias das variáveis de desempenho consumo de ração (CR, g), ganho de peso (GP, g), conversão alimentar (CA), taxa de mortalidade (TM, \%) e índice de eficiência produtiva (IEP) dos frangos de corte alimentados com dietas fareladas ou peletizadas, com ou sem enzimas no período de 21 dias

\begin{tabular}{|c|c|c|c|c|c|}
\hline Tratamentos & CR & GP & $\mathrm{CA}$ & $\mathrm{TM}$ & IEP \\
\hline T1 (controle farelada) & 1121,66 & 764,90 & 1,46 & 0,00 & 263,16 \\
\hline T2 (controle peletizada) & 1065,18 & 817,96 & 1,30 & 4,17 & 302,00 \\
\hline T3 (reformulada farelada com CE) & 1115,46 & 751,43 & 1,48 & 0,00 & 255,50 \\
\hline T4 (reformulada farelada sem CE) & 1092,53 & 753,15 & 1,45 & 0,00 & 262,16 \\
\hline T5 (reformulada peletizada com CE) & 1133,88 & 841,31 & 1,34 & 16,66 & 269,66 \\
\hline T6 (reformulada peletizada sem CE) & 1139,55 & 842,75 & 1,35 & 8,33 & 288,83 \\
\hline $\mathrm{CV} \%$ & 7,3923 & 5,532 & 6,799 & 369,6 & 23,763 \\
\hline \multicolumn{6}{|l|}{ Contraste simples } \\
\hline $\mathrm{T} 1$ vs $\mathrm{T} 2$ & ns & 0,0453 & 0,0063 & ns & ns \\
\hline $\mathrm{T} 1$ vs T5 & ns & 0,0054 & 0,0423 & ns & ns \\
\hline $\mathrm{T} 1 v s \mathrm{~T} 6$ & ns & 0,0045 & 0,0481 & ns & ns \\
\hline $\mathrm{T} 2$ vs $\mathrm{T} 3$ & ns & 0,0140 & 0,0023 & ns & ns \\
\hline $\mathrm{T} 2$ vs $\mathrm{T} 4$ & ns & 0,0163 & 0,0122 & ns & ns \\
\hline $\mathrm{T} 3 v s \mathrm{~T} 5$ & ns & 0,0014 & 0,0175 & ns & ns \\
\hline T3 vs T6 & ns & 0,0011 & 0,0201 & ns & ns \\
\hline $\mathrm{T} 4 v s \mathrm{~T} 5$ & ns & 0,0016 & ns & ns & ns \\
\hline $\mathrm{T} 4 v s \mathrm{~T} 6$ & ns & 0,0013 & ns & ns & ns \\
\hline
\end{tabular}

$\mathrm{CE}=$ complexo enzimático, $\mathrm{ns}=$ não significativo $(\mathrm{P}>0,05), \mathrm{CV}=$ coeficiente de variação 
$\mathrm{Na}$ Tabela 3, pode-se observar efeito significativo dos tratamentos sobre o peso corporal pré-abate $(\mathrm{P}=0,0003)$ e sobre o rendimento de coxa e sobrecoxa $(\mathrm{P}=0,0470)$ aos 21 dias de idade. Os frangos que receberam ração peletizada apresentarm maior peso, comparados com os que receberam ração farelada, independente da presença do CE. Isso é confirmado quando o resultado obtido com a ração farelada foi contrastado com o da ração peletizada, ambas sem CE, pela análise de contraste simples $(\mathrm{P}=0,0052)$.
Para o rendimento de coxas e sobrecoxas, observou-se que foi significativo o contraste dietacontrole peletizada $x$ dieta peletizada sem CE, em que as aves que receberam dietas peletizadas, sem $\mathrm{CE}$, apresentaram menor rendimento. Isso se explica pelo fato de essa dieta ser reformulada e não conter enzimas que atuariam na liberação dos nutrientes, melhorando o rendimento de coxas e sobrecoxas.

Com se observa na Tabela 4 , não foram encontradas diferenças significativas no conteúdo de minerais nos ossos e na resistência óssea aos 21 dias de idade.

TABELA 3. Peso vivo pré-abate (PVPA), em gramas, rendimento de peito (RP), em percentual, e rendimento de coxa e sobrecoxa (RCSCox), em percentual, dos frangos de corte alimentados com dietas fareladas ou peletizadas, com ou sem enzimas, no período de 21 dias

\begin{tabular}{|c|c|c|c|}
\hline Tratamentos & PVPA & RP & $\mathrm{RCxSCx}$ \\
\hline T1 (controle farelada) & 793,00 & 17,94 & 3,89 \\
\hline T2 (controle peletizada) & 878,00 & 18,24 & 4,00 \\
\hline T3 (reformulada farelada com CE) & 798,33 & 18,33 & 4,21 \\
\hline T4 (reformulada farelada sem CE) & 805,33 & 18,70 & 3,78 \\
\hline T5 (reformulada peletizada com CE) & 891,33 & 19,03 & 3,83 \\
\hline T6 (reformulada peletizada sem CE) & 901,66 & 19,16 & 3,45 \\
\hline $\mathrm{CV}(\%)$ & 5,779 & 6,534 & 9,990 \\
\hline Valor P & 0,0003 & ns & 0,0470 \\
\hline \multicolumn{4}{|l|}{ Contraste simples } \\
\hline $\mathrm{T} 1 v s \mathrm{~T} 2$ & 0,0052 & & ns \\
\hline $\mathrm{T} 1$ vs $\mathrm{T} 5$ & 0,0015 & & $\mathrm{~ns}$ \\
\hline $\mathrm{T} 1$ vs T6 & 0,0006 & & $\mathrm{~ns}$ \\
\hline $\mathrm{T} 2$ vs $\mathrm{T} 3$ & 0,0083 & & $\mathrm{~ns}$ \\
\hline $\mathrm{T} 2$ vs $\mathrm{T} 4$ & 0,0151 & & ns \\
\hline $\mathrm{T} 2$ vs $\mathrm{T} 6$ & $\mathrm{~ns}$ & & 0,0195 \\
\hline $\mathrm{T} 3 v s \mathrm{~T} 5$ & 0,0025 & & \\
\hline $\mathrm{T} 3 v_{s} \mathrm{~T} 6$ & 0,0009 & & 0,0018 \\
\hline $\mathrm{T} 4 v s \mathrm{~T} 5$ & 0,0047 & & $\mathrm{~ns}$ \\
\hline $\mathrm{T} 4$ ss $\mathrm{T} 6$ & 0,0018 & & ns \\
\hline
\end{tabular}

$\mathrm{CE}$ - complexo enzimático, ns= não significativo $(\mathrm{P}>0,05), \mathrm{CV}=$ coeficiente de variação.

TABELA 4. Médias das variáveis resistências óssea da tíbia (ROT, expresso em Newton), resistência óssea do fêmur (ROF expresso em Newton) e determinação de cinzas $(\mathrm{Cz}, \%)$, dos frangos de corte alimentados com dietas fareladas ou peletizadas, com ou sem enzimas, no período de 21 dias

\begin{tabular}{lccc}
\hline Tratamentos & ROT & ROF & $\mathrm{Cz}$ \\
\hline T1 (controle farelada) & 7583,33 & 9750,00 & 52,381 \\
T2 (controle peletizada) & 10916,66 & 10333,33 & 52,186 \\
T3 (reformulada farelada com CE) & 8333,33 & 9583,33 & 51,533 \\
T4 (reformulada farelada sem CE) & 8166,66 & 10416,66 & 51,708 \\
T5 (reformulada peletizada com CE) & 9083,33 & 11083,33 & 51,498 \\
T6 (reformulada peletizada sem CE) & 9500,00 & 9250,00 & 54,168 \\
CV $(\%)$ & 25,187 & 15,192 & 3,823 \\
Valor P & $\mathrm{ns}$ & $\mathrm{ns}$ & $\mathrm{ns}$ \\
\hline
\end{tabular}

$\mathrm{CE}=$ complexo enzimático, $\mathrm{ns}=$ não significativo $(\mathrm{P}>0,05), \mathrm{CV}=$ coeficiente de variação. 
Na Tabela 5 são apresentados os resultados da cor do músculo peitoral maior (Pectoralis major) de frangos de corte aos 21 dias de idade. Não foi observado efeito significativo $(\mathrm{P}>0,05)$ dos tratamentos sobre a coloração da carne de frango de corte aos 21 dias. A coloração da carne pode variar em função da espécie, das características bioquímicas do músculo, da idade, do sexo, das raças, da nutrição, da gordura intramuscular e das condições de abate (NORTHCUTT et al., 1997). O músculo esquelético das aves é constituído por um músculo branco, formado predominantemente por fibras glicolíticas, pobres em mioglobina, e músculo vermelho, constituído predominantemente por fibras oxidativas com poucas reservas lipídicas (BANKS, 1992). A tonalidade varia em função do estado de oxigenação (ou de oxidação) da mioglobina e depende também do estado químico desse pigmento, assim como da estrutura do músculo, que reflete a luz, e de fatores externos, tais como oxigenação e temperatura. Isso tem importância, pois o grau de maciez e a coloração da carne são características importantes para o consumidor. Além das características produtivas, a qualidade da carne dos frangos tem sido considerada, uma vez que as características sensoriais, como aparência e maciez da carne, são exigidas pelo consumidor (BERAQUET, 2000).

TABELA 5. Coloração do músculo peitoral maior (Pectoralis major) de frangos de corte com 21 dias de idade, medida no sistema $\mathrm{L} * \mathrm{a} * \mathrm{~b} *(\mathrm{~L}=$ luminosidade; $\mathrm{a}=$ intensidade de vermelho; $\mathrm{b}=$ intensidade de amarelo)

\begin{tabular}{lccc}
\hline Tratamentos & $\mathrm{L}$ & $\mathrm{a}$ & $\mathrm{b}$ \\
\hline T1 (controle farelada) & 42,54 & 9,86 & 2,82 \\
T2 (controle peletizada) & 41,69 & 10,09 & 2,75 \\
T3 (reformulada farelada & 43,40 & 8,59 & 2,99 \\
com CE) & & & \\
T4 (reformulada farelada & 42,95 & 9,32 & 2,81 \\
sem CE) & & & \\
T5 (reformulada peletizada & 42,77 & 9,51 & 3,75 \\
com CE) & & & \\
T6 (reformulada peletizada & 43,20 & 10,44 & 3,75 \\
sem CE) & 8,15 & 21,59 & 71,48 \\
CV (\%) & 0,7427 & 0,1291 & 0,6291 \\
Valor P & & &
\end{tabular}

$\mathrm{CE}=$ complexo enzimático, $\mathrm{ns}=$ não significativo $(\mathrm{P}>0,05), \mathrm{CV}=$ coeficiente de variação.

\section{CONCLUSÕES}

A peletização das dietas na temperatura de $75^{\circ} \mathrm{C}$ não causa efeito deletério na atividade enzimática do complexo enzimático utilizado e o uso de rações peletizadas melhora os índices produtivos de frangos de corte criados até 21 dias de idade.

\section{REFERÊNCIAS}

ALBINO, L. F. T.; BÜNZEN, S.; ROSTAGNO, H. S. Ingredientes promotores de desempenho para frangos de corte. In: SEMINÁRIO DE AVES E SUÍNOS, 7., 2007, Belo Horizonte, MG. Anais.... Belo Horizonte: AveSui Regiões, 2007. p.73.

BANKS, W.J. Tecido muscular. In: Histologia veterinária aplicada. 2. ed. São Paulo: Manole, 1992. p. 215- 236.

BEDFORD, M. R. Efeito del uso de enzimas digestivas en la alimentacióne de aves. Avicultura Profesional, v. 14, n. 4, p. 24-29, Winter 1996.

BERAQUET, N.J. Influência de fatores ante e post mortem na qualidade da carne de aves. Revista Brasileira de Ciência Avícola, v. 1, n. 3 , p. 155-166, 2000.

BORGES, F. M. O. Utilização de enzimas em dietas avícolas. Cadernos Técnicos da Escola de Veterinária da UFMG, n. 20, p. 5-30 1997.

BUSTANY, Z. A. The effect of pelleting an enzyme-supplemented barley-based broiler diet. Animal Feed Science Technology, v. 58, p. 283-288, 1996.

CALET, C. The relative value of pellets versus mash and grain in poultry nutrition. Poultry Science, v. 21, p. 23-52, 1965.

COSTA, F.G.; CLEMENTINO, R.H.; JÁCOME, I.M.T.D.; NASCIMENTO, G.A.J.; FLEMMING, J.S.; MONTANHINI NETO, R.; ARRUDA, J.S.; FRANCO, S.G. Efeito da forma física e do valor de energia metabolizável da dieta sobre o desempenho de frangos de corte. Archives of Veterinary Science, v. 7, n. 2, p. 27-34, 2002.

FRANCESCH, M. Bases de la utilización de complejos enzimáticos en avicultura. In: Curso de Especialización Avances en Nutrición Alimentación Animal, 12., 1996, Madrid. Anais... Madrid: FEDNA, 1996. p. 118-131. Disponível em <www.etsia.upm.es/fedna/ capitulos/96capituloVIII.pdf $>$. Acesso em: 16 de jun. 2010.

GARCIA, O. Enzimas: recentes contribuições para a sua aplicação em nutrição animal. In: .Desempenho de frangos de corte alimentados com ração contendo farelo de arroz e enzimas. 
Ciência Agrotecnica, Lavras. v.27, n.6, p.1385, nov./dez., 2003. Disponível em <www.editora.ufla.br/revista/27_6/art24.pdf>. Acesso em: 16 de jun. 2010.

HAMILTON, R.M.G.; PROUDFOOT, F.G. Ingredient particle size and feed texture: effects on the performance of broiler chickens. Animal Feed Science and Technology, v. 51. n. 3-4. p. 203-210, 1995.

KLEIN, C. H.; KESSLER, A. M.; PENZ, A. M. J. Efeito da forma física da ração sobre alguns parâmetros do metabolismo energético de frangos de corte. In: REUNIÃO ANUAL DA SOCIEDADE BRASILEIRA DE ZOOTECNIA, 32., 1996, Brasília, DF. Anais... 1996. Brasília, DF. p. 482-483.

LECZNIESKI, J. L. Considerações práticas do uso de enzimas. In: SEMINÁRIO INTERNACIONAL DE AVES E SUÍNOS, 5., 2006, Florianópolis, SC. Anais.... AveSui, 2006. p. 34-46.

LEITE, J. L. B.; RODRIGUES, P. B.; FIALHO, E. T.; FREITAS, R. T. F.; NAGATA, A. K.; CANTARELLI, V. S. Efeito da peletização e adição de enzimas e vitaminas sobre o desempenho e aproveitamento da energia e nutrientes em frangos de corte de 1 a 21 dias de idade. Ciência Agrotecnica, Lavras, v. 32, n. 4, p. 1292-1298, jul./ago., 2008. Disponível em <http://www.scielo.br/pdf/cagro/ v32n4/a39v32n4.pdf>. Acesso em: 16 de jun. 2010.

MCLAREN, K. The development of the CIE $1976\left(\mathrm{~L}^{*} \mathrm{a}^{*} \mathrm{~b}^{*}\right)$ uniform colour space and colour-difference formula. Journal of the Society of Dyers and Colourists, p. 338-341, 1976.

NORTHCUTT, J.K.; SAVAGE, S.I.; VEST, L.R. Relationship between feed withdrawal and viscera condition of broiler. Poultry Science, v. 76, p. 410-414, 1997.
REDDY, C. V.; JENSEN, L. S.; MERRIL, L. H.; McGINNIS, J. Influence of pelleting on metabolizable and productive energy of a complete diet for chickens. Poultry Science, v. 40, p. 1466, 1961.

ROSE, R.J.; ARSCOTT, G. H. Further studies on the use of enzymes, soaking and pelleting barley for chickens. Poultry Science, v. 39 , p. $1288,1960$.

SARTORI, J. R. Uso de enzimas em rações. Disponível em: < http://www.bichoonline.com.br/artigos/aa0041.htm> Acesso em: 22 nov. 2007.

TORRES, D.M.; COTTA, J.T.B.; TEIXEIRA, A.S.; MUNIZ, J.A.; FONSECA, R.A.; SANTOS E.C.; ALVES, E.L. Dietas à base de milho e farelo de soja suplementada com enzimas na alimentação de frangos de corte. Ciência Agrotécnica, v. 27, n. 1, p. 199-205, 2003.

WYATT, C.L.; BEDFORD, M.R. Uso de enzimas nutricionais para maximizar a utilização de nutrientes pelos frangos de corte em dietas à base de milho: recentes progressos no desenvolvimento $\mathrm{e}$ aplicação prática. In: SEMINÁRIO TÉCNICO FINNFEEDS, 1998, Curitiba. Anais... Curitiba: Finnfeeds, 1998. p. 2-12.

ZANELLA, I.; SAKOMURA, N.K.; SILVERSIDES, F.G.; FIQUEIRDO, A.; PACK, M. Effect of Enzyme Supplementation of Broiler Diets Based on Corn and Soybeans. Poultry Science, v.78, p.561-568, 1999. Disponível em <http://ps.fass.org/cgi/ reprint/78/4/561>. Acesso em: 16 de jun. 2010. 